\title{
A REDE DE INTERNET E AS COMUNIDADES ARTÍSTICAS: UM NOVO PONTO DE ENCONTRO VIRTUAL
}

Inês Albuquerque ${ }^{1}$ e Paulo Cezar Barbosa Mello

\section{Reflexões iniciais}

A rede de Internet assumiu-se, a partir da década de 90 do século XX, como um meio de divulgação por excelência das novas formas de arte produzidas em e para o ambiente virtual. A partir das suas próprias características de meio de informação de alcance imediato e global, e no contexto da adoção das novas tecnologías para a produção artística, a Internet tornou-se um meio de criação e divulgação privilegiado. Neste contexto, tem dado origem a um novo ponto de encontro - virtual - de grupos de artistas e investigadores, que, organizados de acordo com interesses comuns, no que respeita à discussão e criação artística, apresenta uma nova forma de produção, divulgação e também de socialização.

Algumas novidades possibilitaram, a todos os artistas, uma nova forma de pensar e fazer arte. Exigiram que a poética não se restringisse ao valor ou aura de uma obra em sí, mas principalmente ao diálogo propiciado por ela. A evolução dos suportes - meios pós-modernos talvez proporcionou a expansão da percepção, alteração a fruição passiva, para a interacção. Este novo campo artístico surge, assim, como um espaço para novas formas de viver e pensar a arte, contribuindo para o surgimento de novos papéis para a obra de arte, tal como para o observador e o criador (artista).

A preocupação da contemporaneidade, do perceber/criar a arte que acontece no momento, passou a ser o mote de toda a arte interativa. A

\footnotetext{
1 Inês Albuquerque: Universidad del País Vasco |Breve Currículo: Bacharel/Licenciatura em Design de Comunicação pela Escola Superior de Tecnologias e Artes de Lisboa, doutoranda no programa Pensamiento y Praxis en El Arte Actual da Facultad de Bellas Artes - Universidad del País Vasco. Professora da Universidade Sénior da Ajuda, Lisboa. http://lattes.cnpq.br/7428311180515262

2 Paulo Cezar Barbosa Mello: Pesquisador pela USP - Programa Interunidades em Estética e História da Arte (ECA, FAU, FFLCH) | Breve Currículo: Graduado em Comunicação Social - Publicidade e Propaganda pela Fundação Casper Líbero, especialista em Design de Hipermídia pela Universidade Anhembi Morumbi e mestre em Estética e História da Arte pela Universidade de São Paulo (2006). Professor na Universidade São Judas Tadeu e na Universidade Presbiteriana Mackenzie e diretor de criação/designer na PMStudium Comunicação e Design Ltda Me.

http://lattes.cnpq.br/2766104772518381
} 
interatividade na criação, na fruição, na divulgação e propagação passou a ser condice sine qua non para as obras contemporâneas: "Quando a informação se move a uma velocidade elétrica, o mundo das tendências e dos rumores torna-se o mundo real" (MacLuhan). O tempo, nesta realidade, é somente velocidade - o instantâneo e o simultâneo.

Deve-se levar em conta neste pensamento estético a união que não somente à arte é permitida, mas a todas as ciências. Uma informação migrada do analógico para o digital, ganha repercussões inimagináveis, além de se identificar uma nova forma do saber, a qual reúne os mais diversos assuntos. Os vários aspectos da linguagem humana estão, agora, reunidos no mesmo espaço.

Estamos num “...momento de extraordinaria importância na história da produção artística contemporânea, capaz de confundir seculares sistemas teóricos disciplinares, e de modificar profundamente o sentido do trabalho artístico, vivido em toda a sua plenitude somente por uma parte da consciência artística contemporânea..." (Mário Costa, 1995).

\section{Criação artística na rede de Internet}

A rede de Internet é hoje um dos meios, por excelência, de criação e de divulgação de novas formas de produção artística que iniciaram o seu desenvolvimento a partir dos anos 90 do século passado.

As novas possibilidade que, com a rede de Internet, se abriram no campo artístico, são, antes de mais, fruto das características deste novo meio de comunicação. Além de conduzir a uma nova estética muito particular, diretamente relacionada a este novo meio tecnológico, as especificidades da rede contribuiem para a definição de um novo tipo de arte, através das suas características:

- Interactividade, pois a comunicação na rede implica uma interacção entre meio, computador e utilizador;

- Acesso global, pois é acessível em qualquer lugar do mundo, desde que exista uma ligação à rede e um computador para possibilitar essa mesma ligação;

- Dinamismo, pois a rede de Internet está sempre num contínuo processo de construção e reconstrução à medida que se adiciona ou se retira informação;

- É um meio de comunicação imediato e em tempo real;

- Tenta ser um meio no qual a comunicação está organizada de forma não hierárquica: o modelo de comunicação na rede baseia-se em intereses comuns por parte dos usuários;

- Permite a interacção simultânea entre vários usuários, apesar da sua localização geográfica;

- Necessita da utilização de uma interface, isto é, de um qualquer objecto ou símbolo real ou virtual que actúa como mediador da comunicação homem-máquina. 
Neste novo meio cultural desenvolvem-se várias formas de expressão artística. No âmbito deste trabalho considera-se apenas toda a expressão artística produzida em e para a rede, que de forma geral se inclui no que se denomina de arte de Internet ou net.art. É esta nova forma de arte que, no que respeita às comunidades artísticas, possibilita a existência de vários núcleos de criação plástica/discussão teórica, que de acordo com as contingências sociais da rede, agrupam um certo número de elementos com interesses comuns. A existência de comunidades artísticas não é uma situação nova no mundo da arte pois já no final do século XIX Paul Gauguin e Vicent Van Gogh tentaram criar uma comunidade de pintores em França. No início do século $\mathrm{XX}$, com as vanguardas, também encontramos comunidades artística, como as representativas do expressionismo alemão, os grupos Die Brücke e Der Blaue Reiter. A novidade, atualmente, é o meio no qual estas comunidades se desenvolvem, e o tipo de arte que é o ponto de partida de algumas destas mesmas comunidades. Na questão que apresentamos, o mundo virtual, a rede de Internet e a arte de Internet são os pontos de partida para o desenvolvimento de comunidades artísticas virtuais.

O mundo da rede de Internet é um mundo virtual, que no ambiente da cibercultura é denominado de ciberespaço. O ciberespaço é um novo espaço que está além da materialidade, e que se realiza enquanto virtual num paralelismo à realidade "real" na qual nos movemos. Este mundo virtual é tão real quanto qualquer outro, no entanto menos palpável, e é um espaço de relações e de trocas. A virtualidade não é mais do que uma características decorrente da evolução tecnológica aplicada ao nosso quotidiano. É então neste espaço virtual que encontramos uma nova forma de expressão artística que é a arte de Internet, cujas características que a definem de uma forma geral são:

- Interactividade;

- Natureza efémera;

- Carácter virtual e não material;

- Difusão pública através de um meio de comunicação;

- Multiplicidade de pontos de acesso à obra;

- Experiência imediata e participação do usuário;

- Novas funções para artista, obra e observador;

- Estética particular.

É possível comprender, através desta abordagem ao tema do trabalho, que um novo meio de comunicação como a rede de Internet possibilita e condiciona a criação artística, e origina novos pontos de 
encontro virtuais cuja regra é somente a existência de um interesse comum a todo o grupo. O desenvolvimento das novas tecnologias permitiu a existência deste novo espaço comunitário no qual se criam novas relações entre usuários que ultrapassam o domínio do real.

\section{Estética: A percepção de um meio no meio}

“(...) O poder definidor da hipermídia está na sua capacidade de armazenar informações e, através da interação do receptor, transmuta-se em incontáveis versões virtuais que vão brotando na medida mesma em que o receptor se coloca em posição de co-autor. Isso só é possível devido à estrutura de caráter hiper, não sequencial, multidimensional que dá suporte as infinitas ações de um leitor imersivo.”3 (Lucia Santaella, 2000 p:13).

Expandindo o territorialismo da internet a um sentido mais abrangente, apenas para compreender a inserção do homem neste novo meio, encaramos a hipemídia. Toda a retórica a cerca da hipermídia permeia as definições de espaço, suas compreensões e até mesmo sua poética. No entanto é necessário firmar o compromisso com a filosofia estética para perceber a extensão de sua atuação como suporte de criação e não apenas de propagação.

A estética defendida por Kant vai além do estudo do belo ou do sensível apenas, ele insiste na importância da consciência estética para a vida como um todo. Uma percepção do estado natural do ser humano. Kant pregava que essa capacidade de fruição estética está intimamente ligada às outras faculdades do ser humano, essencialmente as cognitivas ${ }^{4}$, mesmo afirmando que a percepção estética independe de conhecimento prévio.

O espaço segundo Kant não pode ser percebido, pois não é uma propriedade das coisas, mas sim do tempo ${ }^{5}$. O espaço é então uma sobreposição às coisas baseada na intuição que se tem delas. Extrapolando o conceito apregoado por Kant sobre o espaço, pode se dizer que a

3 Lúcia Santaella em prefácio do livro Hipermídia: psicanálise e história da cultura de Sérgio Bairon e Luis Carlos Petry

4 Aqui tomo por faculdades cognitivas não apenas o processo cognitivo formal, ditados pela pedagogia/psicologia, mas por junção e de vários autores e conclusão própria, como o processo inerentemente humano de dedução por conhecimento teórico (aprendido) e intuitivo (natural) uma episteme e techne grega.

5 "Crítica da razão pura" de 1781 
hipermídia é a representação temporal de um espaço inexistente e constante, pois ele apenas surge no momento da interação. Um «memento mori» digital.

Esta percepção do espaço kantiano é um pouco do retorno à cultura da oralidade mágica, onde a relação do homem com o ambiente fomenta a criatividade garantindo uma percepção sinestésica, que, é também um reflexo da reorganização dos sentidos, do pensamento e do conhecimento humano, proporcionado pelas tecnologias. A sinestesia é uma evidente característica do ambiente hipermidiático, pois propicia, em um espaço momentâneo, o estímulo aos diversos sentidos.

Este estímulo acontece em função do hibridismo que é peculiar no meio digital. A gama de recursos de produção de linguagens e processos comunicacionais convergem para um mesmo objetivo, a percepção. $\mathrm{O}$ espaço hipermidiático é o catalizador de todas as linguagens, tornando-se uma própria. Esta linguagem se apropria dos mesmos princípios $^{6}$ que caracterizam o hipertexto e que norteiam sua existência acirrando ainda mais as formas de hibridismo:

- a metamorfose constante que permite adaptações sem limites;

- a heterogeneidade que faz das inúmeras conexões, associações colaborativas e ecléticas;

- multiplicidade e de encaixe de escalas, onde cada elemento formador do meio é um ponto de origem, como se fosse o originador do meio;

- exterioridade que garante a independência do espaço a qualquer forma de dispositivo ou elemento, seu crescimento ou diminuição é associativo e independente;

- topologia, a linguagem não tem um espaço, ela é o próprio espaço e

- a mobilidade, seus múltiplos centros de conexão garantem sua expansão sempre que necessário.

O espaço criado por esta nova linguagem, é um ambiente de percepção. A informação já não é mais recebida, mas sim percebida. Em um espaço em que tudo é linguagem, tudo é informação. A percepção humana é então aqui bombardeada de estímulos - som, imagem e em determinadas situações, olfato, paladar e tato. A imersão do usuário complementa a característica híbrida da hipermídia, pois é a relação homem-ambiente que efetivamente confirma o aspecto contemporâneo no sentido literal do termo -, a interatividade, principalmente a linguagem e a existência do meio. Neste espaço multidimensional - considerando que cada sentido ocupe uma dimensão própria e completa - o usuário é ao mesmo tempo, fruidor passivo, autor, co-autor e mais uma vez fruidor. A

${ }^{6}$ Pierre Lévy - 1993 p:25-26 
estrutura maleável do espaço hipermidiático faz com que a interação seja condição constante, pois o usuário passa a fazer parte da dinâmica espaçotempo.

É nesta condição de interatividade e contemporaneidade que se forma uma nova estética, ou como diz Couchot, uma tecnoestética ${ }^{7}$. Uma percepção do sensível que se expande aos periféricos humanotecnológicos-digitais, dando ao usuário diferentes recursos perceptivos. E de acordo com Roy Ascott, "estamos entrando no mundo-mente (Worldmind) e nossos corpos estão desenvolvendo a faculdade da cibercepção (cyberception) - isto é, a amplificação tecnológica e o enriquecimento de nossos poderes de cognição e percepção".

Assim, considerando o ciberespaço, ou ousando esbarrar na definição de Einstein e chamar de hiperespaço, um espaço para "alojar ${ }^{8 "}$ lembranças, esquecimentos, arte, história, fatos e até mesmo um novo universo com regras distintas, pode-se facilmente estender todo o 'ambiente' hipermidiático à uma extensão da cognição humana. É no espaço de Francastel, no entanto, que surge à mente ao mencionar os processos cognitivos, pois para ele o espaço é uma experiência própria do homem. Um espaço onde a presença o torna existente e o poder criativo não tem limite, pois é atemporal e o processo, seja ele qual for, inicia-se sempre no agora.

A percepção dentro da hipermídia é uma mescla das duas abordagens psicológicas conhecidas, a construtivista no qual o a percepção do mundo é construída a partir das informações do ambiente - o conhecimento prévio transforma, distorce, amplia ou descarta o alvo da percepção - e da abordagem ecológica que argumenta que a percepção é um processo direto e continuo que ocorre através da exploração em colaboração com os outros sentidos. Aqui se configura claramente a relação do espaço com o usuário, pois a interação com o ambiente não é apenas um processo passivo de aprendizado, mas sim de aquisição de conhecimento e integração da nova informação em sua "rede semântica,

\footnotetext{
Diana Domingues explica em seu artigo "ciberarte:zonas de interação" como sendo "uma denominação empregada por Edmond Couchot e Pier Luigi Capucci, entre outros especialistas em arte e tecnologia, para falar de uma estética que explora a dimensão sensível das tecnologias e seus efeitos sobre os nossos sentidos extendidos por suas capacidades expressivas".

8 Termo literal utilizado por Bachelard em seu livro a poética do espaço
} 
elaborando e reestruturando seus modelos mentais e suas estruturas cognitivas"9.

No viés das poéticas pode-se atribuir à hipermídia, a característica onírica do devaneio ${ }^{10}$, onde o tempo se dobra em reverência ao espaço e o único momento é o presente, sem trajeto, sem demoras, sem antes ou depois. O ser humano comunga com o subconsciente e o inconsciente, neste plano de sonhos imaginativos, durante seu sono, onde trafega de lugares nunca antes visto a novas localidades ao virar da cabeça. Este espaço único é uma metáfora natural à imaginação, sem limites, pudores ou mesmo receios. É evidente que a hipermídia não é (até o término deste material pelo menos) uma dimensão na qual o usuário possa dominar e concretizar todos os seus desejos físicos, mas onde a única limitação desta "casa ${ }^{11}$ " é efetivamente a imaginação humana.

A hipermídia e todas as suas metáforas nada mais é do que a evolução dos conceitos humanos em torno de uma ferramenta, magicamente se transformando em uma habilidade coletiva. Habilidade esta já herdada pelos próprios códigos genéticos ${ }^{12}$, que carregam informações e experiências complexas, tornando a cada geração indivíduos mais habituados às tecnologias e seus raciocínios. Poder este que apenas a divina alquimia humana é capaz de prover.

As mídias digitais, computador mais comumente pensado, tornaram-se realmente uma extensão do corpo, um fiel companheiro obediente, domesticado, incansável e sem terminações nervosas que limitem as experiências. A capacidade de fazer e desfazer um experimento sempre vai existir. Nunca mais a primeira vez será a última, mas sempre "única", singular, pois todas as vezes serão como primeiras. O ciclo interminável de tentativas e erros dão chances a novos acertos, fincando ainda mais a necessidade da cabeça pensante humana no espaço hipermidiático.

A tecnologia, mais propriamente dita a tecnologia digital, acrescentou uma interessante aceleração ao mundo. A hipermídia é um

9 Kozma, 1991

${ }^{10}$ Acompanhando Bachelard em a Poética do Devaneio, tem-se: “(...) o devaneio é uma atividade onírica na qual subsiste a clareza da consciência" ( $\mathrm{p}: 144)$.

11 A casa de Bachelard em "A Poética do Espaço"

12 A natureza humana e a própria vida são também participantes ativos das novas tecnologias, estudos e experimentos como a bioinformática, a nanotecnologia, a bioarte, a arte transgênica são caminhos já muito utilizados por artistas e pesquisadores da hipermídia e da arte contemporânea. 
espaço dentro de um ambiente maior, toda uma cultura. Vive-se novamente um momento mágico, poético, repleto de metáforas e referências sensórias que cria uma nova percepção, a percepção digital. Nesta nova percepção é a arte que move o salto evolucionário dentro do hiperespaço, pois é ela que permite uma viagem sensorial, por destinos desconhecidos garantindo uma entrega física e a total imersão psicológica, gerando estímulos novos e experiências perfeitas a cada viagem. A arte hoje é feita nas extensões do corpo, conhecido como computador, formas que já nascem binárias, prontas para serem experimentadas em um espaço que desconhece a fronteira da distância, pois estão a apenas uma conexão de distância.

A propriedade intelectual é, na hipermídia, mais um item que caracteriza a arte. A criação nasce em um espaço, mas sua fruição não necessariamente tende a ser inerte ou passiva, ela tende a ser criativa, colaborativa, a arte não é mais monopólio de um, mas de uma coletividade. A imersão propiciada pelo meio é a alma da obra, onde a participação irrestrita faz com que ela seja sempre inacabada. Existe sempre mais material para esta obra, é uma fonte inesgotável de idéias e percepções.

A hipermídia é um espelho do homem, um novo apêndice criativo. O Ciberespaço é então um meio de criação sem limitações, no entanto para que se possa ser com ele, é necessário um diálogo, uma compreensão desta linguagem tão dicotômica. A percepção de um ambiente, onde flui o pensamento lógico, como extensão dos processos racionais humanos é a chave criadora. Para que haja esta interação é necessário uma tradução de códigos e sinais. No ambiente hipermidiático toda forma de comunicação é possível. A utilização de textos, orais e verbais, imagens, sons, cores, formas, referências sensórias é sempre transformada em comunicação.

É nesta situação que os processos cognitivos são provados, reforçados com novidades e diferentes aprendizados. Em ambientes hipermidiáticos, utilizam-se interfaces interativas, pois são elas que garantem a contínua vivência do usuário dentro do espaço. Assim, reforçase a necessidade de uma interface que permita "ao usuário obter uma visão panorâmica do conteúdo, navegar na massa de dados sem perder a orientação e, por fim, mover-se no espaço informacional de acordo com seus interesses ${ }^{13}$ ".

${ }^{13}$ BONSIEPE (1997, p:59) 
Torna-se então necessário a compreensão da extensão do termo interface. Segundo Lévy ${ }^{14}$ "a palavra 'interface' designa um dispositivo que garante a comunicação entre dois sistemas informáticos distintos ou um sistema informático e uma rede de comunicação. [...] Uma interface homem/máquina designa o conjunto de programas e aparelhos materiais que permitem a comunicação entre um sistema informático e seus usuários humanos". Indo mais além, arrisca-se entender interface como recursos utilizados pelo meio, para interação através de comunicação sensorial cognitiva, pois vai utilizar recursos já conhecidos, como signos verbais, imagens, sons e movimento, em uma linguagem própria ao mesmo tempo coletiva.

Esta coletividade é então uma característica formal do processo cognitivo causado pela hipermídia, pois os novos padrões de reconhecimento tendem a uma mescla de individualismo (personalização) e coletivismo, onde as informações são transformadas e entendidas como interfaces. O processo advindo das tentativas e erros cria caminhos já conhecidos, demarcando formas de acesso como experiências adquiridas que ganham padrões esperados a cada navegação. A estética é então ditada a partir das experiências bem sucedidas. Esta nova estética tende então a determinar as próximas padronizações de interfaces, fazendo com que a experiência seja mais uma vez coletivizada, reiniciando então o processo. Em síntese, a percepção do ambiente hipermidiático tende a ser dinâmico, pois este adapta-se a cada nova experiência, criando novos padrões e novas percepções ditando novas características. $\mathrm{O}$ dinamismo das experiências aproximam-se cada vez mais à velocidade do pensamento, tornando efetivamente uma extensão do corpo humano, todo e qualquer dispositivo de acesso ou que simplesmente facilite a interação com o meio. Não é de se admirar que a portabilidade seja tão comum entre os dispositivos digitais. Atualmente precisa-se cada vez menos de informações ou recursos extras para se realizar qualquer navegação. A informação sobre o meio, já faz parte do usuário e não mais do dispositivo. $\mathrm{O}$ usuário torna-se uno com o meio. Kerckhove ${ }^{15}$ compreende o meio digital (eletrônico) também como um órgão de controle e análise do corpo social. E um órgão também sujeito

\footnotetext{
${ }^{14}$ LÉVY, 1993, p:176

${ }^{15}$ Derrick de Kerckhove. The Skin of Culture (Investigating the New Electronic Reality) foi publicada pela Somerville House Books Limited, Toronto, Ontário, Canadá, em 1995. Tradução: Luis Soares e Catarina Carvalho. Lisboa: Relógio D'Água Editores, março de 1997.
} 
às mudanças sociais, pois, as redes de computadores estão prestes a engolir a televisão e se pulverizar em vários objetos-prótese ligados em rede (roupas, acessórios, veículos, etc), pode-se entender que os padrões de percepção será sempre coletiva, garantido, não apenas para uns poucos, mas principalmente para um coletivo.

\section{Comunidades artísticas: um novo ponto de encontro virtual}

As comunidades virtuais artísticas propagam-se pela rede de Internet a partir dos seus espaços fisicos de origem. Reúnem um conjunto de individuos que se relacionam com base nos seus interesses comuns, radicados não somente na prática, mas também na discussão teórica da arte. A localização geográfica destes artistas e teóricos é indiferente, pois uma comunidade virtual é acessível de qualquer ponto do globo, desde que se cumpram as seguintes premissas básicas: utilização do computador, ligação à rede de Internet, e por parte do usuário o conhecimento / domínio da linguagem simbólica que implica a interação entre este, o computador e o meio de comunicação que é a rede.

Em 1994, no início da difusão da rede de Internet, Howard Rheingold define as comunidades virtuais da seguinte forma: "As comunidades virtuais são agregados sociais que surgem da rede quando uma quantidade suficiente de gente leva a cabo estas discussõs públicas durante um tempo suficiente, com suficientes sentimentos humanos como para formar redes de relações pessoais no espaço cibernático.” (Baigorri e Cilleruelo, 2006). Sem dúvida, isto é o que define uma comunidade virtual de forma geral.

Quando as comunidades virtuais são residência de artistas ou teóricos de net.art, encontramos vários conteúdos teóricos ou de produção artística que rementem à especificidade das comunidades artísticas. Sem dúvida que o ponto de partida é um interesse comum sobre uma forma de expressão artística, seja de sua produção, difusão ou discussão, e este é o mote destes novos pontos de encontro virtuais.

Como exemplo temos a comunidade virtual localizada em Portugal, Atmosferas (http://www.atmosferas.net). Neste espaço virtual Centro de Artes Digitais Atmosferas - cometamos por contactar com o objecto de interesse desta comunidade virtual, a partir da sua própria denominação: artes digitais. É a partir daqui que nos é dada a hipótese de navegar e participar desta comunidade, se está de acordo com os nossos interesses. Temos então vários links disponíveis para consulta, que dispõem de informações sobre as características desta comunidade virtual, que nos 
apresentam os seus membros ou artistas, assim como as suas obras. Uma das iniciativas mais importantes, desenvolvida com o apoio desta comunidade, foi a exposição "Online Portugueses NetArt 1997 | 2004", realizada em 2005. Se já a especificação do tema, net.art em Portugal, tem relevância ao nível da cartografia do trabalho dos net artistas portugueses, a sua importância reside também no fato de ser a primeira exposição em linha de net.art realizada no país, e através de uma comunidade virtual portuguesa. Claro que sabemos que a localização geográfica não é o que define a comunidade virtual, nem os seus membros, mas há que reconhecer a importância deste grupo no panorama artístico português.

O que se destaca, no tema das comunidades virtuais artísticas, é que atualmente se possibilita um ponto de encontro virtual no âmbito artístico. Não apenas artistas, mas também para todos aqueles interessados na arte e nas suas relações com o mundo digital, com o ciberespaço, com a sociedade atual. A novidade destas comunidades virtuais, além da sua existência no ciberespaço, além da sua relação com a arte, é sem dúvida a possibilidade de integrar todos os indivíduos, que, não sendo artistas, têm algum interesse pelo tema. Existe assim uma democratização no acesso às comunidades artísticas, e há também uma participação de pessoas de todos os pontos do mundo, somente possível pela existência em rede.

\section{Considerações finais}

Nas últimas décadas assistimos ao emergir de uma nova plataforma de comunicação, que ofereceu possibilidades inexistentes até então. Em seu redor se organizaram inúmeras comunidades, que representam novas formas de interação entre os indivíduos, e que permitem também a criação de novas formas de comunicação.

No panorama artístico assiste-se também ao emergir de novas comunidades de criação e reflexão centradas no espaço virtual. Além da sua especificidade enquanto comunidade, o campo artístico que é objeto de interesse por parte dos membros destas comunidades está focado na relação entre arte e tecnologia, e particularmente nas artes digitais, nas quais a net.art é o exemplo escolhido no âmbito deste trabalho. Há que aceitar que o espaço da rede de Internet é um novo espaço social, um novo espaço de comunicação, um novo espaço de expressão criativa e artística, e um novo ponto de encontro. Assim, as comunidades virtuais artísticas não são mais do que reflexo das possibilidades da rede, em relação à arte. 


\section{Bibliografia}

BACHELARD, Gaston - A Poética do Espaço, São Paulo: Martins Fontes, 2003.

BAIGORRI, L. e CILLERUELO, L. - Net.Art - Practicas artísticas y politicas en la red, Madrid: Brumaria e Universidad de Barcelona, 2006.

BAIRON, Sérgio, PETRY, Luis Carlos - Hipermídia psicálise e história da cultura, São Paulo: Ed. Mackenzie, 2000.

BENJAMIM, Walter - Obra de arte na sua reprodutibilidade técnica. In: Obras escolhidas, São Paulo: Editora Brasiliense, 1985.

COSTA, Mario - O Sublime Tecnológico. São Paulo: Experimento, 1995.

COUCHOT, Edmond - Da Representação à Simulação. In: Imagem Máquina - A Era das Tecnologias do Virtual. Rio de Janeiro: Editora 34, 1993.

DOMINGUES, Diana (Org.) - A Arte no Século XXI: a bumanização das tecnologias. São Paulo: Editora UNESP, 1997.

FLUSSER, Vilén - Filosofia da Caixa Preta. São Paulo: Hucitec, 1986.

GREENE, Rachel - Internet Art, London: Thames \& Hudson, 2004.

LEVY, Pierre - As tecnologias da inteligência, São Paulo: ed 34, 2001.

LÉVY, Pierre - Cibercultura, Lisboa: Instituto Piaget, 1997.

MACHADO, Arlindo - Máquina e o imaginário, São Paulo: Edusp, 1993.

MACLUHAN, Marshall - O meio é a mensagem. São Paulo: Cultrix, 1996.

NEGROPONTE, Nicholas - A vida digital. São Paulo: Cia. das Letras, 1995.

PACKER, Randall; JORDAN, Ken. Multimedia: from Wagner to virtual reality. NY:W.W.Norton \&Company, 2001.

PANOFSKY, Erwin. O Significado nas Artes Visuais. São Paulo: Perspectiva, 2002. 